\title{
BMJ Open Is Olympic inspiration associated with fitness and physical activity in English schoolchildren? A repeated cross- sectional comparison before and 18 months after London 2012
}

\author{
Gavin R H Sandercock, ${ }^{1}$ Chris Beedie, ${ }^{3,4}$ Steve Mann ${ }^{2,3}$
}

To cite: Sandercock GRH, Beedie C, Mann S. Is Olympic inspiration associated with fitness and physical activity in English schoolchildren? A repeated cross-sectional comparison before and 18 months after London 2012. BMJ Open 2016:6:e011670.

doi:10.1136/bmjopen-2016011670

- Prepublication history and additional material is available. To view please visit the journal (http://dx.doi.org/ 10.1136/bmjopen-2016011670).

Received 31 March 2016 Revised 16 June 2016 Accepted 26 July 2016

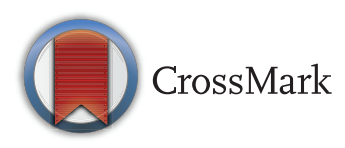

For numbered affiliations see end of article.

Correspondence to Dr Gavin R H Sandercock; gavins@essex.ac.uk

\section{ABSTRACT}

Objectives: To compare cardiovascular fitness and physical activity of schoolchildren 18 months after London 2012 according to Olympic 'inspiration'.

Design: A cross-sectional comparison between groups of schoolchildren categorised according to selfreported Olympic inspiration and a repeated crosssectional comparison using data collected pre-2012.

Setting: Schools within a $50 \mathrm{~km}$ radius of the Olympic Park, Stratford, London.

Participants: 931 students (10.0-15.9-year-olds) attending 6 schools assessed in 2013 and 2014 (18 (range: 14-20) months after London 2012) and 733 students from the same schools assessed in 20082009 (42 (range: 38-46) months before London 2012).

Primary outcome measures: Self-reported Olympic inspiration; cardiorespiratory fitness $\left(\dot{\mathrm{V}} \mathrm{O}_{2 \text { peak }} \mathrm{mL} / \mathrm{kg} /\right.$ $\mathrm{min}$ ) assessed using the $20 \mathrm{~m}$ shuttle-run and selfreported physical activity.

Secondary outcomes measures: Differences in $\dot{\mathrm{V}} \mathrm{O}_{2 \text { peak }}$ before and after London 2012.

Results: $53 \%$ of children reported being inspired to try new sports or activities. Compared with those not inspired by the Games, $\dot{\mathrm{V}} \mathrm{O}_{\text {2peak }}$ was higher in boys $(d=0.43)$ and girls $(d=0.27)$, who continued to participate in activities at $18(14-20)$ months. This $45 \%$ of sample was also more physically active (boys, $d=0.23$; girls, $d=0.38$ ) than those not or only briefly inspired to participate in activities (boys, $d=0.24$; girls, $\mathrm{d}=0.21)$. Compared with pre-2012 values, $\dot{\mathrm{V}} \mathrm{O}_{2 \text { peak }}$ was lower post-2012 in boys $(d=0.37)$ and in girls $(d=0.38)$.

Conclusions: High levels of inspiration to participate in new activities reported following London 2012 and positive associations with fitness are encouraging. We cannot discount the possibility that inspired participants may have already been fitter and more active pre-2012.

These associations must be interpreted in the context of the significant declines in fitness shown by our repeated cross-sectional comparison. Olympic host countries should employ longitudinal monitoring using objectively measured fitness and physical activity to provide evidence of health-related legacy.

\section{Strengths and limitations of this study}

- This is the first study to assess associations between Olympic inspiration and health-related fitness; the use of objectively measured cardiorespiratory fitness is a strength of the study.

- The cross-sectional design is a limitation, as it did not allow the inference of causation.

- Comparing data collected 18 months after London 2012 with those of children attending the same schools 5 years earlier is a strength of the study.

- Sampling of participants at different times following London 2012 and the use of self-reported physical activity are also limitations.

\section{INTRODUCTION}

In 2005, the International Olympic Committee awarded Great Britain the 2012 Olympic Games based on a bid which promised to 'inspire a generation' and 'create a legacy of sport and healthy living'. These promises were made despite no evidence for such effects from previous multisport events. $^{12}$

Prior to London 2012, Shipway ${ }^{3}$ highlighted the need for evidence to justify the economic costs of hosting sporting mega-events. McCartney et $a l^{1}$ found no evidence of health benefits in countries hosting previous mega-events and proposed that 'robust, long-term evaluations' should be put in place to assess the impact of London 2012. Beyond the extant ${ }^{4}$ Active People Survey (APS), none was commissioned.

The APS showed an initial increase of 530000 adults participating in $1 \times 30 \mathrm{~min}$ weekly sports from April 2012 to April 2013. Subsequent data (October 2012-October $2013)^{4}$ showed a decline in the number of 
16-25-year-olds participating in $1 \times 30$ min weekly sport, a trend that has continued. ${ }^{5}$

All of the above metrics are subjective and none are indicative of health as objective measures of physical activity and cardiorespiratory fitness are known to be. ${ }^{6}$ The validity of even the most-detailed, subjective assessments of children's habitual activity is increasingly coming under scrutiny. ${ }^{7}$ Self-reporting or proxy-reporting remains the dominant assessment tool in population-based surveys due to the financial cost, time constraints, participant burden and methodological difficulties of objectively assessing physical activity. ${ }^{7}$ Assessment of cardiorespiratory fitness provides an objective, cost-effective means to assess the health of adults and children. Cardiorespiratory fitness is more strongly related to health status than (particularly self-reported) measures of physical activity. ${ }^{6}$

Our objective was to assess the legacy of London 2012 by examining whether uptake of sports and activities inspired by the Olympics was associated with children's fitness and physical activity and body mass index (BMI). As changes in all three measures have been reported in the past decade, ${ }^{8-10}$ we compared post-London-2012 values with existing data collected in the same schools (2008-2009) as part of the East of England Healthy Hearts Study (EoEHHS). ${ }^{8} 11$

\section{METHODS}

\section{Study design}

Ethical approval was granted by the University Ethics Committee. School, parental and pupil informed consent were also secured ahead of data collection.

The primary outcome measure was cardiorespiratory fitness assessed using the $20 \mathrm{~m}$ shuttle-run test performance converted to estimated $\dot{\mathrm{V}} \mathrm{O}_{2 \text { peak. }}{ }^{12}$ Assuming differences in $\dot{\mathrm{V}} \mathrm{O}_{2 \text { peak }}$ of $2 \mathrm{~mL} / \mathrm{kg} / \mathrm{min}$ (boys) and $1.5 \mathrm{~mL} / \mathrm{kg}$ / min (girls) represent meaningful differences, we calculated that 100 boys and 120 girls per group were needed to achieve statistical significance $(\alpha=0.05, \beta=0.80)$.

Written invitations were sent to nine schools located within $50 \mathrm{~km}$ of the Olympic park (Stratford, London) all of which had participated in previous studies. ${ }^{8}{ }^{11}$ From nine respondents, we selected two secondary (one in a rural area) and four primary (one rural) schools to approximate the population distribution of the study area.

\section{Participants}

For comparability with historical data held for students from these schools, we used the same inclusion and exclusion criteria as previous studies. ${ }^{8}{ }^{11}$ All consenting pupils aged between 10.0 and 15.9 years were eligible for the study. Those with medical conditions, illness or injuries that precluded participation in normal Physical Education (PE) lessons were excluded.

\section{Protocol}

Participants' date of birth was used to calculate decimal age on day of testing. Home postcode was used to calculate area-level deprivation using the English Indices of Deprivation (EID) ${ }^{13}$ and dwelling (rural or urban) using Geoconvert to access data from the National Statistics Postcode Directory. ${ }^{14}$

Stature to nearest $0.1 \mathrm{~cm}$ and mass to nearest $0.1 \mathrm{~kg}$ were measured with participants dressed in standard physical education clothing and without shoes. BMI was calculated $\left(\mathrm{kg} / \mathrm{m}^{2}\right)$ and converted to z-scores. ${ }^{15}$ Cardiorespiratory fitness (fitness) was assessed using the $20 \mathrm{~m}$ shuttle-run performed as the FITNESSGRAM PACER test. ${ }^{16}$ Total shuttle count was recorded and converted to estimated $\dot{\mathrm{V}} \mathrm{O}_{\text {2peak }}(\mathrm{mL} / \mathrm{kg} / \mathrm{min}) .{ }^{12}$ Participants also reported their physical activity over the past 7 days using an English-language version of the Physical Activity Questionnaire for Older Children (PAQ) ${ }^{17}$ which is scored from 1 (very low physical activity) to 5 (highly active).

Inspiration to try, and persistence with, new activities were measured using items adapted from the Chance to Shine Survey, ${ }^{18}$ a proxy report survey deployed after London 2012. To the best of our knowledge, no direct assessments of inspiration were made in schoolchildren before or after London 2012. No metric is reported in the London 2012 Meta-Evaluation Documentation. ${ }^{19}$ Participants were asked a series of questions relating to their engagement with and inspiration by London 2012 (see online supplementary materials). Responses to the following items were used in the present study: 'Have you been inspired to try a new sport or activity since the 2012 Olympic Games?' Participants were provided with a closed (Yes/No) response and were asked not to include activities performed only as part of physical education. Those responding 'Yes' were then asked: 'Which sport or activity ?' and 'Are you still taking part in this sport or activity?' again with a closed (Yes/ No) response.

\section{Data analysis}

We grouped participants according to their self-reported 'Inspiration' as: 'None' if they had not tried a new sport or activity; 'Brief', if they tried new activity but ceased participating 18 (14-20) months after London 2012; 'Continued' if they continued to participate in an Olympic-inspired activity at the time of assessment.

The intraclass correlation coefficient (ICC=betweenschool variance/ (between-school variance+within-school variance)) was calculated to assess whether outcomes clustered within schools. We examined differences in fitness $\left(\dot{\mathrm{V}} \mathrm{O}_{2 \text { peak }} \mathrm{mL} / \mathrm{kg} / \mathrm{min}\right)$ and physical activity (PAQ score) using analysis of covariance (ANCOVA) adjusted for age, area-level deprivation and time of testing. BMI was not adjusted for age as z-scores correct for skewness, kurtosis and age. To examine the potential causative association between physical activity and between-group differences in fitness, ANCOVA was adjusted for physical activity in addition to age, deprivation and time of testing. 
Mean differences $(95 \% \mathrm{CI})$ and standardised effect sizes (Cohen's d) were used to describe between-group differences. We assumed a minimum important effect size of $\mathrm{d}=0.2$ as small, $\mathrm{d}=0.5$ as medium and $\mathrm{d}=0.8$ as large. ${ }^{20}$ All analyses were performed using SPSS V.20 (SPSS, An IBM Company, Chicago, Illinois, USA).

\section{RESULTS}

The sample comprised 931 pupils ( $55 \%$ boys) from school years (grades) 6-11 drawn from six schools. Demographic characteristics and values for outcome measures are presented in table 1 . The sample provided a good representation of the East of England where $93 \%$ of people describe themselves White-British and $71 \%$ of the population lives in urban areas. Area-level deprivation $(\mathrm{EID}=11.6)$ was lower than expected for this part of the region $(\mathrm{EID}=15.6) .{ }^{13}$ There was little evidence of between-school clustering of BMI or physical activity, and the between-cluster ICCs for $\dot{\mathrm{VO}}_{2 \text { peak }}$ were only marginal $(\mathrm{R} \geq 0.10)$. There was evidence of clustering for area-level deprivation but adjusting for this variable reduced ICCs for all outcome measures to $\mathrm{R}<0.06$. We chose, therefore, not to correct for clustering but did adjust all analyses for area-level deprivation.

Overall, $54.3 \%$ of boys and $49.3 \%$ of girls reported being inspired to try a new sport or activity (activities reported are in online supplementary table S1). Of those inspired, $83.3 \%$ of boys and $81.3 \%$ of girls reported that they continued to participate in this sport 1 year later with only $8.5 \%(n=79)$ of participants reporting that they no longer participated.

Table 2 shows mean values by group and results of ANCOVA adjusting for age and deprivation. There were significant main effects for fitness and physical activity in both sexes and a significant main effect for BMI in girls. In boys, post hoc analysis showed that the Continued group was fitter $(\mathrm{d}=0.43)$ and more active $(\mathrm{d}=0.38)$ than the None group. The continued group had higher fitness $(d=0.43)$ and was more active $(d=0.23)$ than the None group. There were no significant differences between boys in the None and Brief groups. Girls classified as Continued were significantly fitter $(\mathrm{d}=0.27)$, more active $(\mathrm{d}=0.34)$ and also had a lower BMI $(\mathrm{d}=0.32)$ than the None group. Girls in the Continued group were more active $(\mathrm{d}=0.24)$ than those in the Brief group. Adjusting for physical activity attenuated the main effect for inspiration on fitness in boys $(\mathrm{F}=2.6, \mathrm{p}=0.075)$. This effect was much greater in girls $(\mathrm{F}=0.74, \mathrm{p}=0.48)$, and no between-group differences in fitness remained significant (all post hoc tests $\mathrm{p}>0.1$ ).

Historical data were available for 733 students $(53 \%$ boys) from the 6 participating schools. Descriptive data are shown in online supplementary table S2. Mean (SD) values for all participants pre-2012 and post-2012 and mean differences between pre-2012 and all post-2012 groups are shown in table 3 . To account for the small $(\mathrm{d}=0.13)$ differences in age (boys, $12.2 \pm 1.4$ years; girls, $11.9 \pm 0.9$ years) between cohorts, all analyses were adjusted for age and area-level deprivation.

Post-2012, boys' $\dot{\mathrm{V}} \mathrm{O}_{2 \text { peak }}$ was $2.0 \quad(95 \%$ CI 0.9 to $3.2) \mathrm{mL} / \mathrm{kg} / \mathrm{min}$ lower than the pre-2012 mean $(\mathrm{d}=0.38)$. Post hoc analysis showed significantly lower $\mathrm{VO}_{2 p e a k}$ in the None and Brief groups compared with boys assessed pre-2012. Compared with pre-2012, BMI (z-score) was lower overall $(\mathrm{d}=0.30)$ and across all post-2012 groups.

Girls' $\mathrm{VO}_{2 \text { peak }}$ was also $2.1(95 \%$ CI 1.3 to 3.0$) \mathrm{mL} /$ $\mathrm{kg} / \mathrm{min}$ lower post-2012 $(\mathrm{d}=0.37)$. Post hoc analysis

Table 1 Demographic characteristics, outcome measures, engagement and Olympic inspiration in schoolchildren from the East of England measured 18 \pm 2 months following London 2012

\begin{tabular}{|c|c|c|c|c|}
\hline & $\begin{array}{l}\text { Boys, } n=513 \\
\text { Mean (SD) }\end{array}$ & $\begin{array}{l}\text { Girls, } n=418 \\
\text { Mean (SD) }\end{array}$ & Boys' ICC & Girls' ICC \\
\hline Age & $12.4(1.46)$ & $12.3(1.50)$ & & \\
\hline$\dot{\mathrm{V}} \mathrm{O}_{2 \text { peak }}(\mathrm{mL} / \mathrm{kg} / \mathrm{min})^{\star}$ & $44.2(5.4)$ & $40.1(5.6)$ & $\mathrm{R}=0.11$ & $R=0.12$ \\
\hline Physical activity (PAQ) & $2.92(0.72)$ & $2.58(0.61)$ & $R=0.10$ & $R=0.09$ \\
\hline BMI $\left(\mathrm{kg} / \mathrm{m}^{2}\right)$ & $19.1(4.1)$ & $19.8(4.4)$ & & \\
\hline BMI (z-score) & $0.32(1.42)$ & $0.39(1.24)$ & $R=0.09$ & $R=0.08$ \\
\hline Deprivation (EID) & $11.6(5.0)$ & $11.7(6.5)$ & $R=0.27$ & $R=0.31$ \\
\hline Ethnicity (White-British) & $93 \%(n=477)$ & $92.5 \%(n=387)$ & & \\
\hline Urban $\ddagger$ & $73 \%(n=138)$ & $75 \%(n=104)$ & & \\
\hline Ruralf & $27 \%(n=375)$ & $25 \%(n=314)$ & & \\
\hline \multicolumn{5}{|l|}{ Followed 2012 Olympics } \\
\hline A lot & $57.2 \%(n=293)$ & $60.1 \%(n=251)$ & & \\
\hline A little & $42.8 \%(n=220)$ & $39.9 \%(n=167)$ & & \\
\hline Inspired to try new activity & $54.3 \%(n=279)$ & $49.3 \%(n=206)$ & & \\
\hline Continued at 12 months & $45.2 \%(n=232)$ & $40.0 \%(n=167)$ & & \\
\hline \multicolumn{5}{|c|}{$\begin{array}{l}\text { *Estimated from } 20 \text { m shuttle-run using the equation of Leger et al (1988). }{ }^{12} \\
\text { †Defined using the International Obesity Task Force criteria. } \\
\text { fUrban included urban, town and fringe, rural includes villages and isolated dwellings (National Statistics Postcode Directory, 2010). } \\
\text { BMI, body mass index, Z-score calculated using the UK1990 Growth Reference (Cole et al, 1995); EID, English Indices of Deprivation (Office } \\
\text { for National Statistics, 2010); ICC, intracluster correlation coefficients; PAQ, Physical Activity Questionnaire for Adolescents. }\end{array}$} \\
\hline
\end{tabular}


Table 2 Fitness, physical activity and BMI in 10-15.9-year-olds from the East of England measured 18 months after London 2012 according to self-reported Olympic inspiration

\begin{tabular}{|c|c|c|c|c|}
\hline & \multicolumn{3}{|c|}{ Olympic inspiration group } & \multirow[b]{2}{*}{ ANCOVA } \\
\hline & $\begin{array}{l}\text { None } \\
\text { Mean (SD) }\end{array}$ & $\begin{array}{l}\text { Brief } \\
\text { Mean (SD) }\end{array}$ & $\begin{array}{l}\text { Continued } \\
\text { Mean (SD) }\end{array}$ & \\
\hline \multicolumn{5}{|l|}{ Boys } \\
\hline $\mathrm{V}_{2 \text { peak }}(\mathrm{mL} / \mathrm{kg} / \mathrm{min})^{*}$ & $43.4(4.9)$ & $43.2(4.1)$ & $45.4(6.0) \dagger$ & $\begin{array}{l}F=9.35 \ddagger \\
p<0.001\end{array}$ \\
\hline Physical activity (PAQ) & $2.78(0.70)$ & $2.88(0.75)$ & $3.04(0.65) \S$ & $\begin{array}{l}F=8.84 \uparrow \\
p<0.001\end{array}$ \\
\hline BMI (z-score) & $0.32(1.42)$ & $0.35(0.97)$ & $0.39(1.21)$ & $\begin{array}{l}F=0.23 \ddagger \\
p=0.798\end{array}$ \\
\hline \multicolumn{5}{|l|}{ Girls } \\
\hline$\dot{\mathrm{V}} \mathrm{O}_{2 \text { peak }}(\mathrm{mL} / \mathrm{kg} / \mathrm{min})^{*}$ & $39.5(4.6)$ & $39.9(4.9)$ & $40.9(5.6) \S$ & $\begin{array}{l}F=4.02 \ddagger \\
p=0.019\end{array}$ \\
\hline Physical activity (PAQ) & $2.51(0.68)$ & $2.58(0.62)$ & $2.72(0.55) \S$ & $\begin{array}{l}F=8.229 \\
p<0.001\end{array}$ \\
\hline BMI (z-score) & $0.58(1.15)$ & $0.39(1.14)$ & $0.20(1.24) \S$ & $\begin{array}{l}F=5.94 \ddagger \\
p=0.003\end{array}$ \\
\hline
\end{tabular}

None-participants who had not tried a new sport or activity; Brief-participants who had tried a new activity but discontinued participation by 18 months; Continued-participants who had tried a new activity and who continued to participate at 18 months.

${ }^{*} \dot{\mathrm{V}} \mathrm{O}_{2 \text { peak }}(\mathrm{mL} / \mathrm{kg} / \mathrm{min})$ estimated from 20 m shuttle-run test using the equation of Leger et $\mathrm{al}^{12}$

†Value is significantly (Bonferroni post hoc test, $\mathrm{p}<0.05$ ) different to both other groups.

$\ddagger$ Controlling for time of testing and area-level deprivation.

$\S$ Value is significantly (Bonferroni post hoc test, $\mathrm{p}<0.05$ ) different from 'None' group.

ๆControlling for time of testing, area-level deprivation and decimal age.

${ }^{*}$ Physical activity is 7 -day self-reported value $(1-5)$ from the PAQ. ${ }^{17}$

ANCOVA, analysis of covariance; BMI, body mass index presented as age-normalised and sex-normalised z-score based on UK1990 Growth Reference ${ }^{17 a}$; PAQ, Physical Activity Questionnaire for Adolescents. ${ }^{17}$

revealed that $\dot{\mathrm{V}} \mathrm{O}_{2 \text { peak }}$ was significantly lower in all post-2012 groups compared with pre-2012 (table 3). The difference in BMI between pre-2012 and post-2012 was trivial $(\mathrm{d}=0.12)$. There was, however, a significant main effect (ANCOVA) and post hoc analysis showed a significantly lower BMI in the Continued group compared with the pre-2012 mean. There were no significant differences in physical activity overall or by group in either sex.

\section{DISCUSSION}

The self-reported data regarding inspiration are broadly comparable with those of the Chance to Shine Survey. ${ }^{18}$ Fifty-four per cent of parents reported that their children had been inspired to try a new sport or activity following London 2012. These cross-sectional findings are encouraging as they indicate that schoolchildren who continued to participate in new activities inspired by London 2012 were fitter, more active and had a lower BMI (girls only) than those not inspired (None). Brief inspiration or short-term participation in new activities was not, however, associated with higher fitness, physical activity or lower BMI. This might suggest that legacy development activities should focus on supporting children to help them maintain participation in any activities inspired by London 2012. This exact sentiment was expressed before London $2012^{3}$ and following other mega-events. ${ }^{21}$ It is well-established that the positive association between fitness and physical activity is stronger when current, rather than historical activity levels are considered. $^{22}$ Those inspired by London 2012 were more active and fitter than their less inspired peers. While boy's BMI varied little between groups, adjusting for physical activity greatly attenuated between-group differences in $\dot{\mathrm{V}} \mathrm{O}_{\text {2peak }}$.

These findings all indicate higher physical activity as the most likely explanation for higher fitness in those continuing to participate in Olympic-inspired activities. It was not possible to recruit a control group who were not exposed to London 2012 and our study design means we cannot infer causality or directionality between associations. It may be that many of the Continued group were already engaged in sport and fitter than schoolchildren not reporting take up of new activities. In the most recent wave of Taking Part, ${ }^{23}$ $24.3 \%$ of respondents already regularly physically active and participating in sport reported that London 2012 had motivated them to increase participation. When assessed in 2011, 7\% of active respondents reported motivation to increase participation compared with only $1.5 \%$ of respondents who did not regularly participate in sport. This figure rose to $5.9 \%$ following London 2012 but has since then it has not been reported in the Taking Part survey.

The encouraging findings showing favourable fitness, physical activity and BMI values in those still participating in Olympic-inspired activities are in stark contrast to those of our comparison of these measures with those made 5 years previously. Compared with children 


\begin{tabular}{|c|c|c|c|c|c|c|c|}
\hline & \multicolumn{2}{|l|}{ Mean (SD) } & \multirow[b]{2}{*}{ Effect size } & \multicolumn{3}{|c|}{ Mean difference $(95 \% \mathrm{Cl})$ vs pre-2012 } & \multirow{2}{*}{$\begin{array}{l}\text { ANCOVA } \\
\text { (main effect }\end{array}$} \\
\hline & Post-2012 (n=513) & Pre-2012 $(n=407)$ & & None & Brief & Continued & \\
\hline \multicolumn{8}{|l|}{ Boys } \\
\hline$\dot{\mathrm{V}} \mathrm{O}_{\text {2peak }}(\mathrm{mL} / \mathrm{kg} / \mathrm{min}) \dagger$ & $44.2(5.4)$ & $46.2(5.4)$ & $d=0.37$ & $-2.7(-1.8$ to -3.9$) \dagger$ & $-3.0(-5.0$ to -1.0$) \dagger$ & $-0.7(-1.7$ to 0.3$)$ & $\begin{array}{l}F=12.1 \\
p<0.001\end{array}$ \\
\hline Physical activity (PAQ) & $2.92(0.75)$ & $3.02(0.75)$ & $d=0.14$ & $-0.10(-0.25$ to 0.19$)$ & $0.05(-0.11$ to 0.26$)$ & $0.08(-0.06$ to 0.28 & $\begin{array}{l}F=0.99 \\
p<0.395\end{array}$ \\
\hline \multirow[t]{2}{*}{ BMI (z-score) } & $0.32(1.24)$ & $0.71(1.18)$ & $d=0.30$ & $0.36(0.25$ to 0.64$) \dagger$ & $0.39(0.06$ to 0.83$) \dagger$ & $0.33(0.15$ to 0.58$) \dagger$ & $\begin{array}{l}F=7.6 \\
p<0.001\end{array}$ \\
\hline & Post-2012 (n=418) & Pre-2012 $(n=366)$ & & None & Brief & Continued & \\
\hline \multicolumn{8}{|l|}{ Girls } \\
\hline$\dot{\mathrm{V}} \mathrm{O}_{2 \text { peak }}(\mathrm{mL} / \mathrm{kg} / \mathrm{min})^{*}$ & $40.1(5.6)$ & $42.2(6.6)$ & $d=0.37$ & $-2.9(-1.8$ to -3.9$) \dagger$ & $-2.4(-4.5$ to -0.4$) \dagger$ & $-1.3(-2.4$ to -0.2$) \dagger$ & $\begin{array}{l}F=10.4 \\
p<0.001\end{array}$ \\
\hline Physical activity (PAQ) & $2.55(0.65)$ & $2.58(0.65)$ & $d=0.01$ & $-0.09(-0.21$ to 0.12$)$ & $-0.01(-0.30$ to 0.29$)$ & $0.14(-0.11$ to 0.22$)$ & $\begin{array}{l}F=0.93 \\
p=0.613\end{array}$ \\
\hline BMI (z-score) & $0.39(1.06)$ & $0.52(1.06)$ & $d=0.12$ & $-0.07(-0.13$ to 0.26$)$ & $-0.08(-0.32$ to 0.41$)$ & $-0.37(0.18$ to 0.58$) \dagger$ & $\begin{array}{l}F=5.6 \\
p=0.001\end{array}$ \\
\hline \multicolumn{8}{|c|}{ 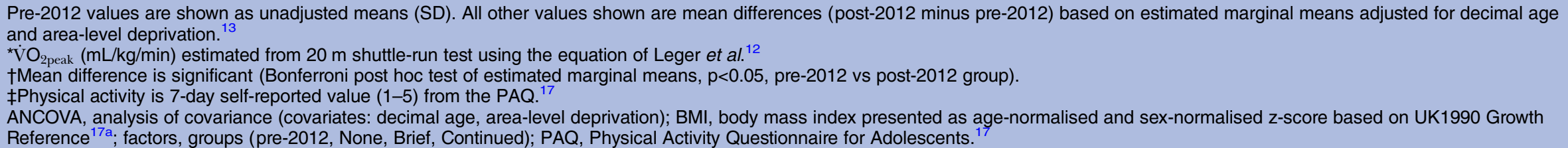 } \\
\hline
\end{tabular}


attending the same schools 5 years earlier, $\dot{\mathrm{V}} \mathrm{O}_{2 \text { peak }}$ was $2 \mathrm{~mL} / \mathrm{kg} / \mathrm{min}$ lower in boys and girls assessed in 20132014 (post-2012). This difference was statistically and clinically significant and is in agreement with reported declines in the cardiorespiratory fitness of children from this region. ${ }^{24}$ Girls' $\dot{V} O_{2 p e a k}$ was lower across all post-2012 groups. The only group mean for $\dot{\mathrm{V}} \mathrm{O}_{2 \text { peak }}$ not significantly lower than pre-2012 was found in the $43 \%$ of boys continuing to participate in new activities 18 months after London 2012. Low cardiorespiratory fitness in childhood is associated with a greater of risk metabolic ill-health in adulthood $^{25}$ and cross-sectional investigation based on data collected in 2007-2008 reported $22 \%$ of $(n=6628) 10$ 16-year-olds had estimated $\dot{\mathrm{V}}_{2 \text { peak }}$ below age-specific and sex-specific criterion values recommended for health. ${ }^{10}$ The present study lacks the statistical power to analyse categorical data. However, applying the same criteria ${ }^{10}$ to the present data reveals that $34.8 \%$ of participants assessed post-2012 had low cardiorespiratory fitness compared with only $22.3 \%$ pre-2012. While the prevalence of low fitness varied from $40.9 \%$ (None) to $35.1 \%$ (Brief) to $27.5 \%$ (Continued) across post-2012 groups, all values were higher than in 2008-2009. Prevalence of low cardiorespiratory fitness was also higher than reported previously in larger studies ${ }^{10}$ of schoolchildren from this region.

The indications that cardiorespiratory fitness is declining seem at odds with the lower BMI values of the post-2012 cohort as there is typically a negative association between performance on weight-bearing tests of $\dot{\mathrm{V}} \mathrm{O}_{\text {2peak }}$ and BMI. ${ }^{9}$ We have previously reported poorer shuttle-run performance accompanied by lower BMI in a repeat cross-sectional study of younger children from this region. ${ }^{24}$ These divergent trends strongly suggest falls in physical activity levels.

The present data represent the first attempt to objectively identify a health-related legacy from hosting an Olympic Games. ${ }^{1}{ }^{2}$ While cross-sectional, our findings suggest some potential benefits to cardiorespiratory fitness, likely mediated by higher physical activity levels, in those inspired to try new activities. The proportion of those sampled who reported continued participation in activities inspired by London 2012 (45\%) is impressive, but it is likely these individuals are those who were already engaged in sport and physical activity. ${ }^{23}$ Our findings must also be interpreted within the context of reports of falling levels of cardiorespiratory fitness and physical activity ${ }^{8-10}$ in English youth. We also found lower fitness overall and across all groups assessed post-2012, providing little that London 2012 has improved health through increased participation in sport. With the exception of the most active subgroup of boys, there is scant evidence that hosting the 2012 Olympic Games has attenuated ongoing ${ }^{24}$ declines in cardiorespiratory fitness. ${ }^{8} 9$

Hopes for a health-related legacy were laid at the feet of the London 2012 organisers despite a total lack of evidence for such an effect following previous Games. ${ }^{1}$ London 2012 did not happen in isolation and many other factors might be responsible for changes in physical activity levels that may have offset any benefits to children's fitness arising from London 2012. The lack of strategy regarding children's activity and health has been compared to neglect. ${ }^{26}$ During the period of this study, and in the run up to London 2012, the government rescinded on the 5-hour offer of PE at schools, cutting funding to the English school sports partnerships scheme. The government also withdrew the previous administration's offer of free swimming for all children. Swimming remains England's most popular sporting activity, ${ }^{4}$ but participation is currently declining. ${ }^{5}$ Reducing opportunities for regular physical activity during $\mathrm{PE}$ and through free swimming may have offset potential benefits from hosting London 2012. The lack of any health-related fitness monitoring either before or since the Games demotes this hypothesis to the level of mere conjecture.

The government's own London-2012 MetaEvaluation ${ }^{19}$ shows the majority of people motivated to increase their participation in sport were already physically active. This 'Matthew Effect' may explain the differences in fitness reported in our cross-sectional analysis. In schoolchildren, this effect is likely driven by the focus on 'competitive sport' as outlined in government's plans for an Olympic legacy ${ }^{27}$ which outlined its commitment to providing a sporting legacy for young people by: 'bringing back a culture of competitive sport in schools'. To do this, the School Games were introduced in 2011 along with increased focus on competitive sports and intraschool competitions from an early age. Such an approach appears paradoxical to the goal of 'getting the whole population more active' as such opportunities are likely to appeal most to those already engaged in sport.

\section{Study limitations}

The sample population is drawn from an area geographically proximal to the Olympic park itself, mostly from commuter towns with direct transport links to Stratford. It is also a predominantly affluent area and one that has benefited from legacy investment projects. We hypothesise that any such impact of London 2012 would be smaller if assessed nationally. Despite calls for the introduction of health-related fitness assessment, ${ }^{28}{ }^{29}$ the continued lack of any such national surveillance leaves such hypotheses untestable. The opportunity sample of schools that volunteered to participate may have produced selection bias, but this is difficult to quantify due to the paucity of nationally representative cardiorespiratory fitness data.

Without longitudinal data regarding physical activity, we cannot infer any cause-and-effect relationship between inspiration, physical activity and fitness. A longitudinal study including objective measures of children's health may have been able to provide more tangible evidence; yet no such data exist for London 2012 or for any other Games. ${ }^{2}{ }^{3}$ This paucity of evidence exists despite recommendations that decision makers should 'include robust, long-term evaluations as part of their design and implementation of events'. 


\section{CONCLUSIONS}

We found evidence for higher cardiorespiratory fitness in the $45 \%$ of schoolchildren who continued to participate in activities inspired by the Olympics 18 months after London 2012. Inspiration alone is not sufficient and our findings reiterate the importance of continued investment in support networks to capitalise on any impetus that hosting major sporting events may provide in promoting health-related behaviour change. ${ }^{3} 2130$

The cost of hosting future mega-events cannot be justified based on the assumption that they will automatically produce health-related benefits. To justify such costs, decision makers must work with key stakeholders to formulate sustainable legacy development plans that include objective longitudinal evaluations of key health outcome measures.

These findings may indicate a health-related legacy from London 2012 but the true scale of which will likely remain undetected due to the lack of appropriate health surveillance measures to assess any impact that events like London 2012 may have.

\author{
Author affiliations \\ ${ }^{1}$ Centre for Sport and Exercise Science, School of Biological Sciences, \\ University of Essex, Colchester, UK \\ ${ }^{2}$ Faculty of Health and Life Sciences, Centre for Applied Biological and \\ Exercise Sciences, Coventry University, Coventry, UK \\ ${ }^{3}$ ukactive Research Institute, London, UK \\ ${ }^{4}$ School of Human and Life Sciences, Canterbury Christ Church University, \\ Canterbury, UK
}

Acknowledgements The authors thank all the schools who participated, the researchers who helped collect the data, Mark Walker at Writtle College for logistical arrangements and Christine Voss for the initial data handling protocols.

Contributors GRHS devised the study and performed the statistical analysis. CB and SM contributed to writing the manuscript. All authors were involved in the final drafting and presubmission revision of the manuscript.

Funding This work was funded by Provide Public Health (Grant: DB0800H1). Competing interests None declared.

Ethics approval University of Essex.

Provenance and peer review Not commissioned; externally peer reviewed.

Data sharing statement No additional data are available.

Open Access This is an Open Access article distributed in accordance with the Creative Commons Attribution Non Commercial (CC BY-NC 4.0) license, which permits others to distribute, remix, adapt, build upon this work noncommercially, and license their derivative works on different terms, provided the original work is properly cited and the use is non-commercial. See: http:// creativecommons.org/licenses/by-nc/4.0/

\section{REFERENCES}

1. McCartney $\mathrm{G}$, Thomas $\mathrm{S}$, Thomson $\mathrm{H}$, et al. The health and socioeconomic impacts of major multi-sport events: systematic review (1978-2008). BMJ 2010;340:c2369.

2. Campbell D. Republished editorial: London's Olympic public health legacy: will it turn to dust? Br J Sports Med 2013;47:687-91.

3. Shipway R. Sustainable legacies for the 2012 Olympic Games. $J$ S Soc Promot Health 2007;127:119-24.

4. Sport England. Active People Survey 7 Oct 2012-Oct 2013. Sport England. London, UK. 2013. https://www.sportengland.org/research/ who-plays-sport/national-picture/ (accessed 1 Jun 2016).
5. Sport England. Active People Survey: once a week participation (National) 14+ APS9 Q2. Sport England. London, UK, 2015. https:// www.sportengland.org/research/who-plays-sport/national-picture/ (accessed 1 Jun 2016).

6. Schmidt MD, Cleland VJ, Thomson RJ, et al. A comparison of subjective and objective measures of physical activity and fitness in identifying associations with cardiometabolic risk factors. Ann Epidemiol 2008;18:378-86.

7. Helmerhorst HJ, Brage S, Warren J, et al. A systematic review of reliability and objective criterion-related validity of physical activity questionnaires. Int J Behav Nutr Phys Act 2012;9:103.

8. Sandercock G, Voss C, McConnell D, et al. Ten year secular declines in the cardiorespiratory fitness of affluent English children are largely independent of changes in body mass index. Arch Dis Child 2010:95:46-7.

9. Stratton G, Canoy D, Boddy LM, et al. Cardiorespiratory fitness and body mass index of 9-11-year-old English children: a serial cross-sectional study from 1998 to 2004. Int J Obes (Lond) 2007;31:1172-8.

10. Sandercock GRH, Ogunleye A, Voss C. Comparison of cardiorespiratory fitness and body mass index between rural and urban youth: findings from the East of England Healthy Hearts Study. Pediatr Int 2011;53:718-24.

11. Voss C, Sandercock G. Aerobic fitness and mode of travel to school in English schoolchildren. Med Sci Sports Exerc 2010;42:281-7.

12. Léger LA, Mercier D, Gadoury C, et al. The multistage 20 metre shuttle run test for aerobic fitness. J Sports Sci 1988;6:93-101.

13. Office for National Statistics. The English Indices of Deprivation 2007 (revised). London: Office of The Deputy Prime Minister, 2007.

14. Office for National Statistics. National Statistics Postcode Directory (NSPD). London: Office for National Statistics, 2007.

15. Cole TJ, Bellizzi MC, Flegal KM, et al. Establishing a standard definition for child overweight and obesity worldwide: international survey. BMJ 2000;320:1240-3.

16. Meredith MD, Welk GJ. Fitnessgram \& Activitygram test administration manual-updated. 4th edn. Champaign (IL): Human Kinetics, 2013.

17. Voss C, Ogunleye AA, Sandercock GR. Physical Activity Questionnaire for Children and Adolescents: English norms and cut-points. Pediatr Int 2013;55:498-507.

17a. Cole TJ, Freeman JV, Preece MA. Body mass index reference curves for the UK, 1990. Arch Dis Child 1995;73:25-9.

18. Chance to Shine. London 2012 Olympics: 100 days on. 2012.

19. Thornton G. 2012 games meta-evaluation: report 5 post-games evaluation summary report. Meta-evaluation of the impacts and legacy of the London 2012 Olympic games and Paralympic games. London (UK): Department for Culture, Media \& Sport, 2013.

20. Batterham AM, Atkinson G. How big does my sample need to be? A primer on the murky world of sample size estimation. Phys Ther Sport 2005;6:153-63.

21. Derom I, Lee D. Vancouver and the 2010 Olympic Games: physical activity for all? J Phys Act Health 2014;11:1556-64.

22. Perusse L, Tremblay A, Leblanc C, et al. Genetic and environmental influences on level of habitual physical activity and exercise participation. Am J Epidemiol 1989;129:1012-22.

23. DCMS. Taking part 2015/16 quarter 3. Taking part. London (UK): Department for Culture, Media and Sport, 2013.

24. Sandercock GRH, Ogunleye A, Voss C. Six-year changes in body mass index and cardiorespiratory fitness of English schoolchildren from an affluent area. Int J Obesity 2015;39:1504-7.

25. Andersen LB, Hasselstrøm H, Grønfeldt V, et al. The relationship between physical fitness and clustered risk, and tracking of clustered risk from adolescence to young adulthood: eight years follow-up in the Danish Youth and Sport Study. Int J Behav Nutr Phys Act 2004;1:6.

26. Weiler R, Allardyce S, Whyte GP, et al. Is the lack of physical activity strategy for children complicit mass child neglect? Br J Sports Med 2014;48:1010-13. doi:10.1136/bjsports-2013-093018 http://bjsm. bmj.com/content/48/13/1010 (accessed 1 Jun 2016).

27. DCMS. Plans for the legacy from the 2012 Olympic and Paralympic games. London, UK: Department for Culture Media \& Sport, 2010.

28. Chief Medical Officer. The 2009 Annual Report of the Chief Medical Officer. London, UK: Department of Health, 2009.

29. ukactive. Generation inactive: an analysis of the UK's childhood inactivity epidemic and tangible solutions to get children moving. London, UK: ukactive, 2015.

30. Mahtani KR, Protheroe J, Slight SP, et al. Can the London 2012 Olympics 'inspire a generation' to do more physical or sporting activities? An overview of systematic reviews. BMJ Open 2013;3 e002058. 